\title{
Age and Diet Affect the Composition of Porcine Colonic Mucins ${ }^{1}$
}

\author{
DOMINIQUE TURCK, ${ }^{2}$ ANDREW S. FESTE, AND CARLOS H. LIFSCHITZ
}

USDA/ARS Children's Nutrition Research Center, Department of Pediatrics, Baylor College of Medicine, Houston, Texas 77030

\begin{abstract}
Colonic mucins may serve as a defense mechanism by binding bacterial, viral, or dietary lectins, thereby preventing them from attaching to the intestinal epithelium. Presumably, the composition of the mucins would be responsible for this phenomenon, and the composition of mucins from mature mammals would be the most effective in binding lectins. To determine whether differences in diet and/or age affect the composition of colonic mucins, we scraped fresh colonic mucosae from pigs at $0(n=3), 7$ $(n=3), 21(n=3)$, and $180(n=3) d$ of age and purified the mucins from these mucosal scrapings. Mucins were purified by ribonuclease and deoxyribonuclease digestion, high-performance size-exclusion chromatography, and cesium chloride density-gradient ultracentrifugation. The 180-d-old pig was considered mature. No changes were observed in any of the variables analyzed in the 7-d-old animals. No changes were observed in quantities of galactosamine and galactose. The amounts of fucose and glucosamine increased by 165 and $37 \%$, respectively, $(p<0.05)$ from $d 0$ to $d 21$ in the sow-fed animals, at which time fucose and glucosamine content were 48 and $22 \%$ greater, respectively, than in the 21 -d-old, artificially fed group ( $p$ $<0.05$ ). A further significant increase in fucose content was observed in the mucins from mature animals. The sulfate content in the 21-d-old, sow-fed animals was significantly lower than in both the newborn and the 21-d-old artificially fed animals. The sulfate content in all three of these groups, however, was significantly higher than that observed in the mucins of mature animals. At $21 \mathrm{~d}$ of age, the protein content was significantly lower than at birth for both diet groups but significantly higher than in the mucins of mature pigs. The evidence indicates that the composition of colonic mucins in 21-d-old sow-fed pigs was more mature than that in the artificially fed counterparts, with respect to fucose, glucosamine, and sulfate. Therefore, if a mature mucin composition is, in fact, a more effective defense against intestinal infection, young breast-fed animals may have an advantage over young artificially fed animals. (Pediatr Res 33: 564-567, 1993)
\end{abstract}

Received July 7, 1992; accepted February 3, 1993.

Correspondence and reprint requests: Carlos H. Lifschitz, M.D., Children's Nutrition Research Center, 1100 Bates St., Houston, TX 77030.

${ }^{1}$ This work is a publication of the USDA/ARS Children's Nutrition Research Center, Department of Pediatrics, Baylor College of Medicine and Texas Children's Hospital, Houston, TX. This project has been funded in part with federal funds from the U.S. Department of Agriculture, Agricultural Research Service under Cooperative Agreement number 58-6250-1-003. The contents of this publication do not necessarily reflect the views or policies of the U.S. Department of Agriculture nor does mention of trade names, commercial products, or organizations imply endorsement by the U.S. Government.

${ }^{2}$ Present address: Service de Pédiatrie, Gastroéntérologie Pédiatrique et Génétique Médicale, Hôpital Claude Hurlez, I Place de Verdun, 59037 Lille, France.
Abbreviations

RNase, ribonuclease

DNase, deoxyribonuclease

Gastrointestinal mucus, the viscous, hydrophilic gel that coats the epithelial lining of the gastrointestinal tract, is a complex mixture of water, electrolytes, macromolecules, enzymes, sloughed cells, Ig and high-molecular-weight glycoproteins called mucins, which are synthesized, stored, and secreted by goblet cells $(1,2)$. Mucins contribute to the lubrication of mucosal surfaces, and they may serve as a mechanism of defense by offering specific binding sites to lectins of bacterial, viral, and/or dietary origin, thus preventing the lectins from attaching to the intestinal epithelium $(3,4)$. Infants, both human and animal, are known to be more susceptible to intestinal infection, particularly if weaned from maternal milk (5). It may be that the mucin composition in the immature host creates a mucosal binding affinity for pathogens that is lower than the mucosal binding affinity in a mature animal. Little is known about the composition of colonic mucins as a function of age or diet. The aim of the present study, therefore, was to determine whether the biochemical composition of colonic mucins could be affected by age or type of feeding. We chose the pig as a model to study mucin development, because its intestinal development and physiology resemble those of a human infant $(6,7)$. The model is limited, however, by the differences in colonic bacterial flora between the infant pig and the human.

\section{MATERIALS AND METHODS}

Concentrated $\mathrm{HCl}$ was purchased from Fisher Scientific Co. (Pittsburgh, PA). Enzyme inhibitors, DNase I (type IV), RNase (type III-A), Trizma, sodium azide, $\mathrm{CsCl}$, carbohydrate standards, and all analytical procedure chemicals, with the exception of the bicinchoninic acid protein reagent (Pierce, Rockford, IL), were purchased from Sigma Chemical Co. (St. Louis, MO). The Bio-Gel 40XL analytical column and guard columns were purchased from Bio-Rad Laboratories (Richmond, CA).

Colons were taken from Pitman-Moore/Hanford strain minipigs (Bastrop Farms, Bastrop, TX) used as controls for other studies. None of the animals had received medications. All protocols were approved by the Animal Care and Use Committee of Baylor College of Medicine and were conducted in accordance with the National Research Council's guide for the Care and Use of Laboratory Animals.

Design. We compared the composition of the colonic mucins of 21 -d-old sow-fed pigs with that of artificially fed pigs and with that of newborn and 180-d-old (mature) animals. The pigs were assigned to one of five groups: group 1 (newborn) animals were killed immediately after birth and before they received any 561 
feeding; group 2 animals were weaned at $3 \mathrm{~d}$ of age, fed an artificial formula, and killed at $7 \mathrm{~d}$ of age; group 3 animals were weaned at $3 \mathrm{~d}$ of age, fed an artificial formula, and killed at $21 \mathrm{~d}$ of age; group 4 animals were sow-fed until they were killed at 21 $\mathrm{d}$ of age, and group 5 (mature) animals were weaned at 28 to 42 $\mathrm{d}$ of age and killed at $180 \mathrm{~d}$ (Table 1).

Feeding regimen. Animals from group 2 (killed at $7 \mathrm{~d}$ ) and group 3 (killed at $21 \mathrm{~d}$ ) were weaned to a standard swine weaning formula (Soweena, Merrick's, Union Center, WI) at $3 \mathrm{~d}$ of age (Table 1). The formula is similar to sow milk in protein, fat, and carbohydrate (lactose) content. Animals in group 5 (killed at 180 d) were weaned to an adult pig food diet.

Colonic scrapings. Colonic mucosal scrapings were obtained from three different litters of pigs at birth and at 7,21, and 180 $\mathrm{d}$ of age. Because of the small quantity of material obtained from newborn and 7-d-old animals, each of the three samples from these two age groups consisted of pooled scrapings from more than one animal of the same litter; i.e. for newborn pigs, one sample resulted from the pooling of the scrapings from three colons, another one from five, and the third sample from the pooling of nine colons (Table 1). For animals in the 7-d-old group, one sample consisted of colonic scrapings obtained from a single animal and the other two samples from two littermates each.

Preparation of colonic mucins. Colons were taken from animals within $1 \mathrm{~h}$ of their death. The abdominal cavity was opened, and the colon was removed and extensively washed with a solution of cold PBS that contained $2 \mathrm{mmol} / \mathrm{L}$ phenylmethylsulfonylfluoride, $3.0 \mathrm{mmol} / \mathrm{L}$ sodium azide, $10 \mathrm{mmol} / \mathrm{L}$ N-ethylmaleimide, and $10 \mathrm{mmol} / \mathrm{L}$ sodium EDTA. The colon was opened along its longitudinal axis, and the mucosa was scraped with a glass slide. Scrapings were stored in $10 \mathrm{mmol} / \mathrm{L}$ Tris-Cl buffer $(\mathrm{pH} 8.0,3.0$ $\mathrm{mmol} / \mathrm{L}$ sodium azide) at $-70^{\circ} \mathrm{C}$ until processing.

Mucins were purified using a previously described method (8). Briefly, the scrapings were homogenized for $30 \mathrm{~s}$ with a Tekmar Tissumizer Mark II (Cincinnati, OH), and centrifuged at 34000 $\mathrm{rpm}$ for $1 \mathrm{~h}$ at $4^{\circ} \mathrm{C}$. The supernatant was dialyzed against Milli$\mathrm{Q}$ water for $2 \mathrm{~d}$ and lyophilized. The sample was then incubated for $16 \mathrm{~h}$ at ambient temperature in PBS that contained bovine DNase I and bovine RNase III-A at a final concentration of 50 $\mu \mathrm{g} / \mathrm{mL}, \mathrm{pH} 7.0$, with $3.0 \mathrm{mmol} / \mathrm{L}$ sodium azide and $10 \mathrm{mmol} /$ $\mathrm{L}$ magnesium sulfate. After incubation, the mixture was centrifuged at $13000 \mathrm{rpm}$ for $30 \mathrm{~min}$. The supernatant was dialyzed against water and freeze-dried.

High-performance size-exclusion chromatography was performed on the colonic mucin preparations after RNase and DNase treatment as previously described (8). Briefly, a Bio-Gel TSK 40XL $(300 \times 7.5 \mathrm{~mm}, 10-\mu \mathrm{m})$ column was used to separate each mucin preparation. The column was equilibrated with 50 $\mathrm{mmol} / \mathrm{L}$ Tris-Cl buffer $(\mathrm{pH} 8.0)$, and the proteins were elute with the same buffer at a flow rate of $1.0 \mathrm{~mL} / \mathrm{min}$; the absorbanc at $230 \mathrm{~nm}$ was used to detect the glycoproteins/proteins. Six mi after injection, $250-\mu \mathrm{L}$ fractions were collected every $1<-f_{n-}$ min. After separation of the sample, a $20-\mu \mathrm{L}$ aliquot was from each fraction and analyzed by high-performance $s$. sion chromatography; the protein-containing fractions that contained the excluded volume were pooled, dialyzed against water. and lyophilized. The sample was then dissolved in $15 \mathrm{~mL}$ of a 4.04-mol/L CsCl PBS solution; the final density of CsCl was 1.42

Table 1. Age, diet, and number of animals used to pre sample studied

\begin{tabular}{rllc}
\hline Age (d) & \multicolumn{1}{c}{ Diet } & Animals/sample & $\begin{array}{c}\text { Samples } \\
\text { studied }\end{array}$ \\
\hline 0 & None & 3,5 , and 9 & 3 \\
7 & Soweena & 1,2 , and 2 & 3 \\
21 & Soweena & 1 & 6 \\
21 & Sow milk & 1 & 3 \\
180 & Sow milk, food & 1 & 3 \\
\hline
\end{tabular}

$\mathrm{g} / \mathrm{mL}$. Density-gradient ultracentrifugation was performed on a Beckman centrifuge (model L2-70 M, Palo Alto, CA) using a vertical-rotor VTi 50 . The sample was spun at $36000 \times g$ for 48 $\mathrm{h}$ at $4^{\circ} \mathrm{C}$. The density of each fraction was determined by weighing a $100-\mu \mathrm{L}$ aliquot. After extensive dialysis against water to remove $\mathrm{CsCl}$, the absorbances at 230 and $260 \mathrm{~nm}$, and neutral hexose values were determined. High-density fractions containing both proteins and carbohydrates were pooled and defined as purified colonic mucins.

Analytical procedures. Proteins were monitored by absorbance at 280 and $230 \mathrm{~nm}$, and concentrations were measured using the bicinchoninic acid method (9). Neutral hexoses were measured using the phenol-sulfuric acid method with galactose as a standard (10). RNA content was assessed by measuring the absorbance at 260 and $232 \mathrm{~nm}$ (11). The DNA content was determined using a fluorimetric method (12). The glucuronic acid content was measured using the method of Bitter and Muir (13).

Hydrolysis of $5 \mu \mathrm{g}$ of mucin glycoprotein for the analysis of neutral sugars and aminosugars was carried out using a gas-phase method (14). After hydrolysis, a 50- $\mu \mathrm{L}$ sample was analyzed by chromatography on a Dionex (Sunnyvale, CA) Carbopak anionexchange column. An isocratic mobile phase consisting of 16 $\mathrm{mmol} / \mathrm{L} \mathrm{NaOH}$ at $1.0 \mathrm{~mL} / \mathrm{min}$ was used to elute the monosaccharides, which were subsequently detected by a Dionex pulsed amperometric detector using a gold electrode.

Sialic acid was determined after hydrolysis by the method of Warren $\left(30 \mu \mathrm{g}\right.$ mucin) with $100 \mathrm{mmol} / \mathrm{L} \mathrm{H}_{2} \mathrm{SO}_{4}$ for $1 \mathrm{~h}$ at $80^{\circ} \mathrm{C}$ (15).

Mucins $(30 \mu \mathrm{g})$ were hydrolyzed with $4.89 \mathrm{~mol} / \mathrm{L}$ formic acid for $24 \mathrm{~h}$ at $100^{\circ} \mathrm{C}$, and sulfate was quantitated by chromatography on a Waters IC-PAK anion exchange column (Waters Associates, Milford, MA). Elution was carried out with borate/gluconate as the mobile phase at a flow rate of $0.8 \mathrm{~mL} / \mathrm{min}$; sulfate was detected using a Waters 430 conductivity detector (16).

Data analysis. An unpaired $t$ test was used to determine whether differences existed between the experimental groups.

\section{RESULTS}

All purified mucin samples were free of DNA, RNA, and glucuronic acid, and the recovery of mucins ranged from 15.6 to $143 \mu \mathrm{g}$ of protein. In addition, SDS-PAGE (under denaturing conditions) of $2.66 \mu \mathrm{g}$ of the mucin protein (d 0,7,21, and 180) revealed no lower molecular weight proteins or glycoproteins. Furthermore, none of the mucin samples entered the separating gel, which indicates that all mucin samples had a high molecular weight (Fig. 1). We did not assess the purity of the mucins by amino acid analysis.

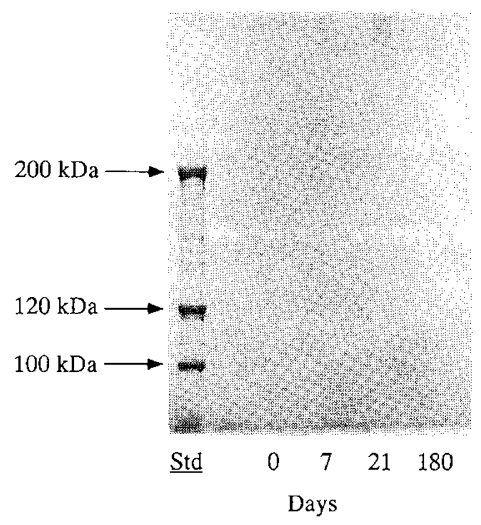

Fig. 1. SDS-PAGE (under denaturing conditions) of $2.66 \mu \mathrm{g}$ of the mucin protein [d 0 (newborns), 7, 21, and 180] revealed no lower molecular weight proteins or glycoproteins. Furthermore, none of the mucin samples entered the separating gel, which indicates that all mucin samples had a high molecular weight. 
The monosaccharide, sulfate, and protein contents of the mucins were expressed in mass terms $(\%$, wt $/ w t)$ rather than moles. Although all the mucins were excluded on the Bio-Gel TSK $40 X \mathrm{X}$ column (exclusion limit $\geq 4000 \mathrm{kD}$ ), the molecular mass of each preparation was not determined. The mucin composition of the 7-d-old animals was unchanged from that of the newborn piglets. No changes related to age or type of feeding were observed in the mucin contents of the monosaccharides galactosamine and galactose. Mucins from the 21 -d-old animals, whether artificially fed $(p=0.04)$ or sow-fed $(p=0.002)$, had a significantly higher amount of fucose than mucins from the newborn animals (Fig. 2). The fucose content of mucins from the 21-d-old, sow-fed group was $48 \%$ greater $(p<0.05)$ than that from the 21-d-old, artificially fed group. The fucose content in the mature mucins was $41 \%$ higher $(p=0.004)$ than that in the 21 -d-old, sow-fed piglets and $60 \%$ higher than that in the 21 d-old, artificially fed piglets.

Mucins from the 21-d-old, sow-fed piglets contained significantly higher amounts of glucosamine than those from newborn animals $(27 \%, p=0.00)$, amounts similar to those found in the mucins of the mature pigs. The glucosamine content of mucins from the 21 -d-old, sow-fed pigs was $22 \%$ greater than that from the artificially fed pigs of the same age $(p=0.03)$, in which glucosamine content was not significantly different from that in newborn animals.

In 21-d-old piglets on either diet, the amount of sialic acid had decreased from the amount in newborn piglets $(p=0.008)$. In the mature pigs, however, the amount of sialic acid in mucins had returned to a level similar to that found in newborn piglets.

In 21 -d-old, sow-fed piglets, the amount of sulfate was significantly lower $(136 \%, p=0.004)$ than in newborn piglets; such was not the case, however, in 21-d-old, artificially fed piglets. An even smaller amount of sulfate was found in the mucins of mature animals.

The protein content of colonic mucins from the 21-d-old piglets in both diet groups was significantly lower than that in newborn piglets $(p=0.01)$, and protein content in the mature pigs was $107 \%$ lower than that in 21 -d-old piglets $(p=0.006$ for sow-fed and 0.016 for artificially fed). The overall increase in the total carbohydrate content and decrease in the protein content of mucins in mature animals resulted in a carbohydrate:protein ratio twice as large as that in the 21 -d-olds and three times as large as that in the newborns.

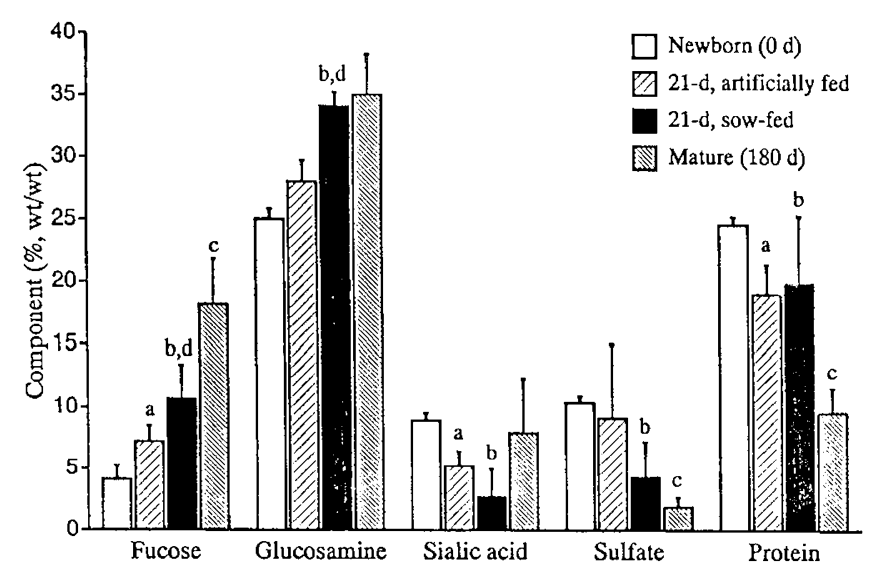

Fig. 2. Relative amounts (\%,wt/wt) of monosaccharides, sulfate, and protein in colonic mucins from four groups of pigs: newborns (never fed), 21-d-olds (artificially fed), 21-d-olds (sow-fed), and 180-d-olds (weaned). Only mucin components that varied significantly with age or diet are represented. $a, \mathrm{~d} 0$ and 21 , artificially fed, significantly different from each other $(p<0.05) ; b, \mathrm{~d} 0$ and 21 , sow-fed, significantly different from each other $(p<0.05)$; $c$, d 180 and 21 , sow-fed, significantly different from each other $(p<0.05)$; $d, \mathrm{~d} 21$, sow-fed and artificially fed, significantly different from each other $(p<0.05)$.

\section{DISCUSSION}

Mucins are high-molecular-weight $\left(>2 \cdot 10^{6} \mathrm{D}\right)$, highly glycosylated $(>70-80 \%$ carbohydrate by weight) glycoproteins that contain various amounts of sulfate and have various ratios of constituent monosaccharides in their carbohydrate moieties, mainly sialic acid, galactose, fucose, $\mathrm{N}$-acetylglucosamine, and $\mathrm{N}$-acetylgalactosamine. The latter is joined by O-glycosidic linkages to the core protein, which is typically rich in serine and threonine (1).

Colonic mucins probably function as mucosal lubricants and protection against infection. The establishment of a mucindegrading flora in the human colon is a gradual process that begins in some infants as early as 3 mo of age $(17,18)$. In the study of structures as complex as mucins, it may be difficult to determine whether changes in composition are the result of differences in their synthesis or bacterial degradation or of the analytical techniques used. To avoid the latter possibility, the material that we purified from pig colonic mucosal scrapings was obtained without the use of proteolytic enzymes, reducing agents, sonication, or other techniques known to fragment mucins. Purified substances were identified as mucins based on the following criteria: absence of nucleic acids (DNA and RNA), absence of glucuronic acid (indicating no significant contamination by glycosaminoglycans), absence of glucose and mannose (determined by anion-exchange chromatography), presence of a high-density fraction (determined by $\mathrm{CsCl}$ equilibrium centrifugation), and presence of a compatible carbohydrate composition. The biochemical characteristics of the purified mucins reported here are similar to those reported in several previous studies of colonic mucins (19-21). Although the descriptions of the composition of colonic mucin vary in the literature, probably as a result of different purification techniques and species differences, our results in the 180-d-old pigs (mature mucins) are comparable to those of Marshall et al. (21), who used the same purification techniques but did not describe the age or diet of the pigs. The main differences in the results of the two studies are in the fucose and glucosamine contents; the contents of both were lower in the Marshall study than in our mature animals (fucose, 10.4 versus $18.6 \%$; glucosamine, 23.9 versus $35 \%$ ). However, we observed that both components can be affected by age and diet.

Little information is available about the developmental pattern of gastrointestinal mucins and the effect that diet may have on their composition. To our knowledge, the present study is the first to show significant differences in the composition of colonic mucins as a result of differences in diet and age. Our findings indicate that significantly more fucose and glucosamine and less sulfate were found in the mucins of the 21-d-old, sow-fed pigs when compared with mucins of the artificially fed animals of the same age. The proportion of glucosamine in the mucins of sowfed animals was not significantly different from that in the mature pigs. In addition, the proportions of fucose and glucosamine in the mucins of 21-d-old sow-fed animals were more like those in the mature animals than were those in the 21-d-old artificially fed animals.

In the mucins of 21-d-old animals, irrespective of diet, i.e. strictly as an effect of age, fucose was significantly increased and sialic acid and protein decreased when compared with the mucins of newborn animals. Further significant changes occurred in the amounts of fucose, sulfate, and protein when mature and newborn mucins were compared.

Shub et al. (22) described differences in physical properties of newborn and adult mucous glycoprotein from rat small intestine. The buoyant density of rat mucins in $\mathrm{CsCl}$ and the mobility of mucins on SDS-PAGE increased progressively and markedly between 14 and $21 \mathrm{~d}$ of age. The functional significance of these differences is not known, but the increases coincide with weaning and occur as other intestinal biochemical functions reach maturity and the secretagogue activity of goblet cells changes (23). These age-related changes in the physical properties of mucus 
may contribute to the maturation of the barrier function of the rat intestinal mucosa, which also occurs in rats between 14 and $21 \mathrm{~d}$ of age. Shub et al. (24) also showed age-related changes in the composition of rat small-intestinal mucin. Newborn rat mucin contained more total protein than adult rat mucin $(27$ versus $18 \%$ ); it also had less total carbohydrate and fewer fucose and galactosamine residues than mucin from adult rats. The sulfate content was greater in mucin from newborn rats $(5.5$ versus $0.9 \%$ ). The decrease in sulfate content with age is consistent with the speculation that a higher degree of sulfation is characteristic of mucous glycoproteins secreted by "immature" goblet cells (25). The developmental changes in rat small-intestinal mucin are similar to those in our study of pig colonic mucin.

Widdowson et al. (26) determined that at birth the piglet has goblet cells in each part of its intestine, some of which are ready for discharge and some of which are "immature". After $24 \mathrm{~h}$, a large proportion of those in the duodenum discharge and are replaced by a new generation of goblet cells. Similar changes take place much more slowly in the large intestine; no important changes are observed before $10 \mathrm{~d}$ of age, a fact that may explain the minimal differences in the biochemical composition of colonic mucins that we observed during the first week after the piglets were born.

The age- and diet-related composition of colonic mucin might be a factor in the greater frequency of gastrointestinal infections in immature and/or weaned infants (5). It has been demonstrated that fucose inhibits the adherence of Shigella flexneri to guinea pig colon (27); fucose may also alter the motility of Entamoeba histolytica in the large bowel (28). Thus, a lower fucose content in mucins (as in the more immature and the artificially fed piglets in our study) may effectively reduce the capacity of mucins to protect the gastrointestinal tract from infection.

In summary, our results demonstrate that age and diet affect the composition of mucous glycoproteins from pig colon. These age- and diet-related changes in colonic mucin composition may affect a mammal's ability to defend itself against intestinal infection.

Acknowledgment. The authors thank Iftikar Khan for his technical assistance, Daryl Friday of Waters Associates for performing the sulfate analysis, and Mary Dudley and Scott Perkinson for performing SDS-PAGE analysis.

\section{REFERENCES}

1. Neutra MR, Forstner JF 1987 Gastrointestinal mucus: synthesis, secretion and function. In: Johnson LR (ed) Physiology of the Gastrointestinal Tract, Vol 2. Raven Press, New York, pp 975-1009

2. Roussel P, Lamblin G, Lhermitte M, Houdret N, Lafitte JJ, Perini JM, Klein A, Scharfman A 1988 The complexity of mucins. Biochimie 70:1471-1482

3. Forstner JF 1978 Intestinal mucins in health and disease. Digestion 17:234263

4. Chadee K, Petri Jr WA, Innes DJ, Ravdin JI 1987 Rat and human colonic mucins bind to and inhibit the adherence lectin of Entamoeba histolytica. J Clin Invest 80:1245-1254
5. Cunningham AS, Jelliffe DB, Jelliffe EFP 1991 Breast-feeding and health in the 1980s: a global epidemiologic review. J Pediatr 118:659-666

6. Fleming SE, Arce D 1986 Using the pig to study digestion and fermentation in the gut. In: Tumblesome ME (ed) Swine in Biomedical Research, Vol 1. Plenum, New York, pp 123-134

7. Pond WG, Haupt KA 1978 The Biology of the Pig. Cornell, Ithaca, NY, pp $40-41$

8. Feste AS, Turck D, Lifschitz CH 1990 High-performance size-exclusion chromatography of porcine colonic mucins: comparison of Bio-Gel ${ }^{(\infty)}$ TSK $40 \mathrm{XL}$ and Sepharose $\left.{ }^{(}\right)$B columns. J Chromatogr 518:349-359

9. Smith PK, Krohn RI, Hermanson GT, Mallia AK, Gartner FH, Provenzano MD, Fujimoto EK, Goeke NM, Olson BJ, Klenk DC 1985 Measurement of protein using bicinchoninic acid. Anal Biochem 150:76-85

10. Dubois M, Gilles KA, Hamilton JK, Rebers PA, Smith F 1956 Colorimetric method for determination of sugars and related substances. Anal Chem 28:350-356

11. Fleck A, Munro HN 1962 The precision of ultraviolet absorption measurements in the Schmidt-Thannhauser procedure for nucleic acid estimation Biochim Biophys Acta 55:571-583

12. Cesarone CF, Bolognesi C, Santi L 1979 Improved microfluorometric DNA determination in biological material using 33258 Hoechst. Anal Biochem 100:188-197

13. Bitter T, Muir HM 1962 A modified uronic acid carbazole reaction. Anal Biochem 4:330-334

14. Hardy MR, Townsend RR, Lee YC 1988 Monosaccharide analysis of glycoconjugates by anion exchange chromatography with pulsed amperometric detection. Anal Biochem 170:54-62

15. Warren L 1959 The thiobarbituric acid assay of sialic acids. $J$ Biol Chem 234:197! -1975

16. Ward DN, Wen T, Bousfield GR 1987 Sulphate and phosphate analysis in glycoproteins and other biologic compounds using ion chromatography: application to glycoproteins and sugar esters. J Chromatogr 398:255-264

17. Norin KE, Gustafsson BE, Lindblad BS, Midtvedt T 1985 The establishment of some microflora associated biochemical characteristics in feces from children during the first years of life. Acta Paediatr Scand 74:207-212

18. Midtvedt AC, Carlstedt-Duke B, Norin KE, Saxerholt $H$, Midtvedt T 1988 Development of five metabolic activities associated with the intestinal microflora of healthy infants. J Pediatr Gastroenterol Nutr 7:559-567

19. Lamont JT, Ventola AS 1980 Purification and composition of colonic epithelial mucin. Biochim Biophys Acta 626:234-243

20. Murty VLN, Downs FJ, Pigman W 1978 Rat-colonic, mucus glycoprotein. Carbohydrate Res 61:139-145

21. Marshall T, Allen A 1978 The isolation and characterization of the highmolecular-weight glycoprotein from pig colonic mucus. Biochem J 173:569578

22. Shub MD, Keku E, Pang KY, Walker WA, Cheng PW 1985 Evidence for biochemical maturation of intestinal mucins during postnatal development. Gastroenterology 88:1585(abstr)

23. Neutra MR, Phillips TH, Phillips TE 1984 Regulation of intestinal goblet cells in situ, in mucosal explants and in the isolated epithelium. In: Ciba Foundation Symposium, Vol 109. Mucus and Mucosa. Pitman, London, pp 20 39

24. Shub MD, Pang KY, Swann DA, Walker WA 1983 Age-related changes in chemical composition and physical properties of mucus glycoproteins from rat small intestine. Biochem J 215:405-411

25. Spee-Brand R, Strous GJAM, Kramer MF 1980 Isolation and partial characterization of rat gastric mucous glycoprotein. Biochim Biophys Acta 621:104-116

26. Widdowson EM, Colombo VE, Artavanis CA 1976 Changes in the organs of pigs in response to feeding for the first $24 \mathrm{~h}$ after birth. II. The digestive tract. Biol Neonate 28:272-281

27. Izhar M, Nuchamowitz Y, Mirelman D 1982 Adherence of Shigella flexneri to guinea pig intestinal cells is mediated by a mucosal adhesin. Infect Immun $35: 1110-1118$

28. Leitch GJ, Dickey AD, Udezulu IA, Bailey GB 1985 Entamoeba histolytica trophozoites in the human and mucus blanket of rat colons studied in vivo. Infect Immun 47:68-73 